\title{
Pesquisa colaborativa: contribuições para a formação didática e o trabalho pedagógico do professor da educação básica ${ }^{1}$
}

\author{
Edileuza Fernandes Silva ${ }^{2}$ \\ Enílvia Rocha Morato Soares ${ }^{3}$ \\ Henrique Rodrigues Torres ${ }^{4}$
}

\begin{abstract}
RESUMO
$\mathrm{O}$ artigo resulta de pesquisa colaborativa, financiada pela FAP-DF, com o objetivo de discutir contribuições das didáticas específicas para a formação e o trabalho pedagógico de professores da educação básica. Analisamos, a partir da abordagem qualitativa, dados levantados de questionários no Google Forms respondidos por 26 professores. Discutimos conceitualmente as didáticas na formação docente, suas contribuições para o trabalho pedagógico e os subsídios da pesquisa colaborativa para a formação de pesquisadores comprometidos com a realidade escolar. Concluímos reafirmando a relevância da formação didática para o trabalho pedagógico com vistas à garantia das aprendizagens de todos os estudantes e da pesquisa colaborativa para a produção de conhecimentos sobre didáticas e formação docente, bem como para a formação dos pesquisadores.
\end{abstract}

PALAVRAS-CHAVE: Educação. Didáticas. Formação de professores. Pesquisa Colaborativa. Trabalho Pedagógico.

\footnotetext{
${ }^{1}$ Financiamento: Fundação de Apoio à Pesquisa do Distrito Federal - FAP-DF.

2 Doutora em Educação. Universidade de Brasília, Brasília, Distrito Federal, Brasil. Orcid: https://orcid.org/00000002-9837-2958. E-mail: edileuzafeunb@gmail.com.

3 Doutora em Educação. Secretaria de Educação do Distrito Federal, Brasília, Distrito Federal, Brasil. Orcid: https://orcid.org/0000-0002-7405-2167.E-mail: enilvia@ hotmail.com.

${ }^{4}$ Doutorando em Geografia. Secretaria de Educação do Distrito Federal/Universidade de Brasília, Brasília, Distrito Federal, Brasil. Orcid: https://orcid.org/0000-0002-2405-5271. E-mail: henriquetorres.sedf@gmail.com.
} 
Collaborative research: contributions to didactic training and pedagogical work of basic education teachers

\begin{abstract}
The article is the result of collaborative research, financed by FAP-DF, with the aim of discussing the contributions of specific didactics to the training and pedagogical work of basic education teachers. Based in a qualitative approach, data collected from questionnaires on Google Forms answered by 26 teachers were analyzed. We conceptually discuss didactics in teacher education, its contributions to pedagogical work and the subsidies of collaborative research for the formation of researchers committed to the reality of the school. We conclude reaffirming the relevance of didactic training for pedagogical work with a view to ensuring that all students acquire skills and collaborative research is successful for the production of knowledge about didactics and teacher training, as well as for the training of researchers.
\end{abstract}

KEYWORDS: Education. Didactic. Teacher formation. Collaborative Research. Pedagogical work.

Investigación en colaboración: contribuciones a la formación didáctica y el trabajo pedagógico de los profesores de la educación básica

\title{
RESUMEN
}

El artículo es el resultado de una investigación en colaboración, financiada por la FAP-DF, con el objetivo de discutir las contribuciones de las didácticas específicas para la formación y el trabajo pedagógico de los profesores de educación básica. Analizamos, desde el enfoque cualitativo, los datos recogidos a partir de los cuestionarios en Google Forms contestados por 26 profesores. Discutimos conceptualmente la didáctica en la formación docente, sus aportes al trabajo pedagógico y los subsidios de la investigación colaborativa para la formación de investigadores comprometidos con la realidad escolar. Concluimos reafirmando la relevancia de la formación didáctica para el trabajo pedagógico con el fin de garantizar el aprendizaje de todos los estudiantes y la investigación colaborativa para la producción de conocimiento sobre la didáctica y la formación de profesores, así como para la formación de investigadores.

PALABRAS CLAVE: Educación. Didáctica. Formación docente. Investigación en colaboración. Trabajo docente. 


\section{Introdução}

O ensino fundamental é a etapa da educação básica que abarca o maior número de estudantes em escolas brasileiras. De acordo com o Censo da Educação Básica do Instituto Nacional de Estudos e Pesquisas Educacionais Anísio Teixeira - INEP (BRASIL, 2020), de um total de 47,3 milhões de matrículas, 26,7 milhões, ou seja, 56,4\%, estão nessa etapa. Os municípios são responsáveis por $68,1 \%$ de matrículas nos anos iniciais, enquanto que aos estados compete a oferta de 41,4\% delas. No Distrito Federal (DF), unidade da federação onde foi desenvolvido o estudo em discussão neste texto, das 543.833 matrículas ofertadas na rede pública de ensino, 50,99\% estão no ensino fundamental, o que representa 277.300 estudantes nessa etapa de ensino (DISTRITO FEDERAL, 2019).

Apesar dos avanços em relação à universalização do ensino fundamental para crianças e jovens de 6 (seis) a 14 (catorze) anos, meta reafirmada no Plano Nacional de Educação 2014-2024 - PNE (BRASIL, 2014), o mesmo não se aplica à garantia de conclusão da etapa na idade recomendada de pelo menos $95 \%$ dos estudantes. Conforme dados do Censo DF de 2020, 50.589 ou 18,24\% dos estudantes do ensino fundamental apresentam defasagem idade/série, caracterizada pelo desnível de dois anos ou mais da idade em relação à série ou ano de escolaridade previsto. Isso sugere a ausência da aprendizagem de conteúdos propostos nos currículos escolares, ou seja, a privação de parte dos estudantes de acesso aos conhecimentos acumulados pela humanidade.

Considerando que na escola pública encontra-se a maioria dos estudantes oriundos de grupos sociais menos privilegiados social e economicamente, essa defasagem é um alerta de que "o deslocamento do processo de exclusão educacional não se dá mais principalmente na questão do acesso à escola, mas sim dentro dela" (MÉSZÁROS, 2008, p. 11). Isso ocorre por meio de mecanismos internos como o trabalho pedagógico que desenvolve, sem desconsiderar, é claro, 
as determinações externas que o influenciam, como é o caso das avaliações externas e das bases curriculares nacionais, entre outras.

Em face dessa realidade, o Grupo de Pesquisa cadastrado no Conselho Nacional de Desenvolvimento Científico e Tecnológico (CNPq), coordenado por professoras da educação superior com experiência de 30 anos em magistério da educação básica e composto por estudantes da graduação, de iniciação científica, da pós-graduação e por docentes vinculados à Secretaria de Educação do DF e à Escola de Formação dos Profissionais da Educação (EAPE-SEEDF), empreendeu esforço teórico e metodológico que envolveu organização conjunta, intencional e planejada para desenvolver pesquisa colaborativa. Essa pesquisa visa compreender: as contribuições das didáticas específicas na formação e no trabalho pedagógico desenvolvido por professores do ensino fundamental da rede pública de ensino do DF, egressos de cursos de licenciatura de uma instituição de ensino superior pública; e os subsídios da pesquisa colaborativa para a formação de pesquisadores comprometidos com a realidade escolar.

A compreensão da colaboração "como o modo ideal de se assegurar o desenvolvimento profissional dos docentes ao longo da carreira, a aprendizagem por excelência para os alunos e a transformação das escolas" (LIMA, 2002, p. 7) permite pressupor que a pesquisa colaborativa produz conhecimentos científicos em uma perspectiva política e educativa. É política por oportunizar a análise de concepções e práticas como a de professores egressos da universidade que, ao mesmo tempo, acolhe e certifica o Grupo de Pesquisa expressando compromisso institucional com o ensino e a pesquisa articulados à rede básica de ensino. E é educativa, por ter a pesquisa caráter formativo para docentes da educação superior, para os estudantes da graduação e iniciação científica, futuros professores da educação básica. Por se constituir em formação continuada dos professores das redes de ensino que dela participam, acreditamos que a pesquisa colaborativa pode, ao mesmo tempo, repercutir em revisão conceitual e prática da formação promovida pela EAPE/SEEDF e, por conseguinte, em mudanças positivas nas escolas. 
Movidos por esses pressupostos, o Grupo assumiu o desafio da pesquisa colaborativa, de abordagem qualitativa, que possibilitou compreender a natureza e a constituição das relações entre pesquisadores e pesquisados, reconstituindo a totalidade para além de uma perspectiva formal do instituído. Buscou-se interpretar a realidade estudada considerando as concepções e práticas dos sujeitos que nela atuam professores egressos de cursos de licenciatura. Essa perspectiva demandou dos pesquisadores uma visão totalizante dos fenômenos do mundo concreto, incluindo seus movimentos dialéticos e suas consequentes transformações, mediadoras das relações entre os indivíduos e a sociedade. Ou seja, considera-se a formação didático-pedagógica em cursos de licenciatura em conexão com as transformações decorrentes das relações no interior da escola e da sala de aula da escola pública.

A opção por um modelo explicativo da realidade, que leve em conta as contradições existentes entre seus elementos para percebê-la a partir do movimento que a vivifica, e a torna mutável e em um processo contínuo de desenvolvimento foi o critério considerado para a definição da epistemologia dialética (WACHOWICZ, 1989), com base na condução deste estudo.

Nessa perspectiva, a metodologia da pesquisa favoreceu o diálogo e contribuiu para a construção colaborativa do conhecimento de forma relacional e dialética entre pesquisadores mais experientes, iniciantes e professores participantes da pesquisa. Esse movimento colaborativo em busca do conhecimento proporcionou e gerou sentidos nas práticas sociais de alternância comunicativa (LINELL, 2009), em que pesquisadores e pesquisados se formam e contribuem para produzir saberes que possibilitem o repensar de concepções e práticas dos sujeitos no movimento favorável à articulação universidade-escola.

$\mathrm{Na}$ perspectiva da pesquisa colaborativa, os pesquisadores assumem a condição de sujeitos produtores da história. Entretanto, sob determinadas condições contraditórias, indicam a necessidade de construção do devir, o que exige uma perspectiva analítica da totalidade 
que considere as unidades teoria-prática (PALUDO, VITÓRIA, 2014), ensino-pesquisa, universidade-escola básica.

Para a produção dos dados foi aplicado questionário on-line a 26 professores dos anos finais do ensino fundamental atuantes em escolas públicas do DF e egressos dos seguintes cursos: Linguagens - Letras Português e Letras Inglês; Educação Física; Artes Visuais; Matemática; Ciências da Natureza; Ciências Sociais - História e Geografia, objetivando analisar suas percepções sobre as didáticas específicas e suas contribuições para o trabalho pedagógico que realizam na escola. Os dados dos questionários foram analisados, procurando conhecer não só o conteúdo das mensagens expressas, mas também o que há "por trás" delas, bem como as ausências nelas percebidas, em um "esforço para evidenciar o silêncio que sempre acompanha as palavras" (SHIROMA et al,. 2005).

Procuramos considerar nesses discursos que "as mensagens expressam as representações sociais na qualidade de elaborações mentais construídas socialmente, a partir da dinâmica que se estabelece entre a atividade psíquica do sujeito e o objeto do conhecimento" (FRANCO, 2008, p. 12). Desse modo, os discursos expressos nos questionários foram analisados com respeito ao contexto em que foram produzidos, permitindo, assim, evidenciar aspectos implícitos ou mesmo ausentes que desvelam representações constituídas por professores egressos de diferentes licenciaturas, sujeitos cujas concepções e práticas revelam processos singulares de constituição do ser docente.

Em termos estruturais, o artigo divide-se em três seções. Na primeira seção discutimos conceitualmente as didáticas na formação do professor da educação básica, demarcando as didáticas específicas por abrangerem o ensino com base no campo epistemológico das disciplinas para as quais se formam professores para atuar nos anos finais do ensino fundamental, foco deste artigo. Na segunda, tendo como referência os elementos estruturantes do trabalho pedagógico, buscamos as contribuições dessas didáticas para a atuação de docentes dos anos finais do ensino fundamental, a partir de 
dados levantados dos questionários. Na terceira seção tecemos considerações acerca das contribuições da pesquisa colaborativa para a compreensão da relação entre formação didática e trabalho docente e para a formação dos pesquisadores comprometidos com a escola e a educação emancipatória.

\section{As didáticas específicas na formação do professor da educação básica}

A escola é o espaço onde o professor desenvolve sua atividade articulando conhecimentos do campo epistemológico, transformados em conteúdos escolares e que dependem de saberes didático-pedagógicos gerais e específicos para, na relação com os estudantes, mediá-los, efetivando o ensino e a aprendizagem. Reconhece-se que todo conteúdo tem uma forma, e o meio como será transmitido é definidor da concepção de educação escolar como prática social progressista ou conservadora (WACHOWICZ, 1989). Assim, "o que vai determinar uma ou outra direção em parte é a didática, pois é o modo de fazer a educação que vai caracterizá-la" (Idem, p. 13). Nessa perspectiva, a Didática e as Didáticas Específicas "necessitam articular-se à ciência pedagógica, numa relação de íntima aderência, uma vez que [,] ausente dos fundamentos pedagógicos que lhe dão suporte, torna-se mera tecnologia" (PIMENTA; FRANCO; FUSARI, 2014, s/p), insuficiente para se realizar o trabalho docente como práxis social transformadora da sociedade.

É essa articulação das didáticas com a ciência pedagógica, que oportuniza aos futuros professores "sólida formação teórica para que possam ler, problematizar, analisar, interpretar e propor alternativas aos problemas que o ensino, enquanto prática social, apresenta nas escolas" (PIMENTA, 2018, p. 17). Os dados de defasagem idade-série apresentados na introdução deste texto revelam um desses problemas, e o seu enfrentamento requer políticas públicas, mas, também, a organização de condições didáticopedagógicas favoráveis às aprendizagens dos estudantes e à realização de pesquisas que integrem professores formadores de professores e docentes atuantes na educação básica em perspectiva colaborativa. 
A formação do professor apenas não é suficiente para melhorar esse cenário. No entanto, "é evidente a necessidade de reforçar a dimensão pedagógica de nossa docência para adaptá-la às condições variáveis de nossos estudantes" (ZABALZA, 2004, p. 38). De acordo com Veiga e Fernandes Silva (2020), essas condições e as demandas das escolas e dos estudantes convocam a discussão da qualidade da formação didática ofertada aos licenciandos, muitas vezes por bacharéis professores sem experiência na educação básica. Isso porque, na formação inicial do professor, a Didática Geral, cujo objeto é o processo de ensino, tem um papel central, pois contempla estudos de aspectos abrangentes, fundamentos do ensinar, como: finalidades, objetivos, seleção e organização de conteúdos escolares, metodologias e técnicas de ensino, avaliação e a relação pedagógica professor-aluno. Da mesma forma, as didáticas específicas, que abrangem as particularidades das áreas de conhecimento, tendo também o ensino como objeto, são igualmente imprescindíveis à formação do futuro professor (VEIGA; FERNANDES SILVA, 2020).

Portanto, discutir a formação docente na didática geral e nas didáticas específicas requer ir além da preocupação com os atos de ensinar, elas são intercomplementares. É preciso contemplar "o processo e as circunstâncias que produzem as aprendizagens e que, em totalidade, podem ser denominados de processos de ensino" (PIMENTA; FRANCO; FUSARI, 2015, s/p).

Em meio às contradições que marcam as realidades dos cursos de formação de professores, partimos do pressuposto de que neles os docentes formadores "conscientes ou não de seus aspectos teóricos como também de suas implicações político-pedagógicas, praticam uma forma de Didática, sob as mais variadas inspirações" (BERBEL, 2013, p. 1). Algumas delas revelam a falta de diálogo entre a Didática Geral ofertada, na maioria das vezes, em faculdades de educação e as didáticas específicas, ministradas em institutos e faculdades da Universidade. Outras inspirações sugerem possibilidades de articulação da didática de cunho mais geral com as didáticas específicas por terem ambas o ensino como objeto de estudo e de pesquisa, explicitam o processo docente do 
conhecimento e vinculam-se à pedagogia, o que atribui intencionalidade formativa ao ato de ensinar (LIBÂNEO, 2008).

A partir desses entendimentos, discutem-se as contribuições das didáticas específicas para o trabalho pedagógico de professores atuantes nos anos finais do ensino fundamental em escolas da rede pública de ensino do DF, egressos das licenciaturas da universidade pesquisada.

\section{Didáticas específicas: contribuições para o trabalho pedagógico}

Embora não seja suficiente, a formação didático-pedagógica do professor vivenciada em cursos de licenciatura é condição necessária e imprescindível para subsidiá-los teórica e metodologicamente com vistas a conceber, executar e avaliar o trabalho pedagógico concretizado na e por meio da relação professor-aluno. Por esse motivo, a formação inicial de professores, as didáticas e o trabalho pedagógico nos anos iniciais do ensino fundamental constituem eixos centrais desta discussão.

Compreende-se o trabalho como práxis transformadora do homem natural em ser social, como atividade histórica intencional adequada a finalidades, que transforma a natureza criando um mundo humano: o mundo da cultura (SAVIANI, 2013). Nessa perspectiva, pelo trabalho, a existência humana é ampliada, incorporando novas necessidades e atividades que precisam ser transmitidas às gerações posteriores para garantir o desenvolvimento dos indivíduos no âmbito da sociedade. "Essa condição de individualidade plural dos homens que os situa na condição de produto e produtor da história (coletiva e particular) é propiciada pelo ato educativo, sendo este concebido nas dimensões política e pedagógica" (SOARES; FERNANDES, 2018, p. 70). Assim, a natureza do trabalho pedagógico requer dos que o realizam autonomia e capacidade para criá-lo, concebê-lo, desenvolvê-lo em um processo de ideação consciente e intencional voltado às finalidades de socializar os conhecimentos das ciências, das artes e da filosofia, historicamente elaborados pela humanidade (DUARTE, 2016). Esses conhecimentos são necessários para que os estudantes 
compreendam a realidade como síntese de múltiplas determinações, desvelando as possibilidades e contradições do gênero humano nesse contexto, incluindo suas dimensões de cunho social, político, econômico e educacional. É pelo trabalho docente, como práxis social (SÁNCHEZ VÁZQUEZ, 2007), que o professor imprime, em parceria com os estudantes, o sentido político e pedagógico às atividades que desenvolve.

Discutir trabalho escolar requer considerar o trabalho como atividade ontológica do ser social e como atividade de estranhamento e alienação, nas condições de relação de exploração do modo de produção capitalista (MÉSZÁROS, 2008). Assim, apesar de o ser humano não se encerrar no trabalho, desconsiderá-lo como o modo pelo qual se produz a própria vida inviabiliza qualquer compreensão de ser humano e de sociedade, bem como de atividade pedagógica desenvolvida na escola e na sala de aula. Dessa determinação, que é recíproca, o trabalho pedagógico comporta especificidades que o distinguem, no âmbito da produção social não material, como atividade formativa deliberada, sistemática e planejada.

A escola é o espaço de acesso à escolarização universal e obrigatória que visa oportunizar aos sujeitos a constituição da natureza humana ou cultural, que não é dada, mas produzida por eles. Tendo por base a natureza biofísica, a educação escolar contribui individualizando e diferindo cada um dos sujeitos, ao mesmo tempo em que os coletiviza e os torna parte de uma história própria, mas, também, social (TCHALEKIAN, 2014).

Dessa forma, o trabalho educativo como "ato de produzir, direta e intencionalmente, em cada indivíduo singular, a humanidade que é produzida histórica e coletivamente pelo conjunto de homens" (SAVIANI, 2013, p. 13) tem, por sua especificidade pedagógica, meios e modos próprios de se realizar, oportunizando, intencionalmente, a apropriação do conhecimento. Sua natureza pedagógica requer dos professores conhecimentos específicos da área de atuação, conhecimentos didático-pedagógicos e compromisso político com a formação dos sujeitos. Para que, de fato, se concretize, a educação escolar deve contribuir para a construção da autonomia intelectual dos indivíduos, 
habilitando-os a agir sobre a realidade de modo a transformá-la e, em decorrência, a modificar a sociedade.

Tomando como base essas reflexões, discutimos as respostas dos 26 professores egressos dos cursos pesquisados sobre a questão: quais foram as contribuições das didáticas específicas para o seu trabalho pedagógico?

Esses professores encontravam-se, em 2019, ano de levantamento dos dados, na faixa etária de 22 a 54 anos, sendo que a maioria tinha entre 22 e 30 anos. São dados que revelam tratar-se de profissionais em fases inicial e intermediária da carreira e que, conforme declararam, investem em suas carreiras por meio da formação continuada fazendo cursos na Coordenação Regional de Ensino (CRE) e na Subsecretaria de Formação Continuada dos Profissionais da Educação (EAPE), participando de estudos na coordenação pedagógica nas escolas e em eventos da área, fazendo leituras por iniciativa própria, pesquisando na internet, estabelecendo parcerias, estabelecendo intercâmbios com colegas e tendo experiências de trabalho.

O tempo total de trabalho dos interlocutores no magistério compreende um período entre 3 e 19 anos, sendo que a maioria tem menos de dez anos atuando nos anos finais do ensino fundamental. $\mathrm{O}$ docente que declarou o maior tempo de docência disse ter 54 anos e trabalhar há dezenove anos com estudantes desse segmento escolar.

No que concerne à carga horária de trabalho semanal, 22 professores trabalhavam 40 horas, três declararam dedicação de 20 horas de trabalho semanal e apenas um trabalhava 60 horas. Destaca-se que os professores da rede pública de ensino do DF contam com o regime de jornada ampliada, ou seja, das 40 horas trabalhadas semanalmente, quinze são destinadas à coordenação pedagógica e 25 à regência de classe. As atividades desses professores são desenvolvidas em uma mesma escola.

Em relação à formação acadêmica, os docentes declararam ter cursado as seguintes licenciaturas: Matemática, Geografia, Ciências Biológicas, Artes Visuais, Artes Plásticas, Educação Física, LetrasPortuguês e as Respectivas Literaturas, Letras-Inglês Licenciatura, 
História, Letras-Espanhol, Licenciatura em Letras - Língua Francesa e Respectiva Literatura. A pós-graduação foi cursada por treze docentes, sendo oito lato-sensu (especialização) e cinco stricto-sensu (mestrado). A rede pública de ensino do DF contava, no ano da pesquisa, com um total de 26.660 professores, sendo: 18.193 (73,78\%) com especialização; 1.888 (7,66\%) com mestrado; e 286 (1,1\%) com doutorado (EAPE, 2020), sendo que os demais, ou seja, $6.293(23,6 \%)$ tinham apenas graduação.

As análises foram realizadas considerando os elementos estruturantes das didáticas específicas que integram o trabalho pedagógico dos professores: a) objetivos de aprendizagem; b) conteúdos; c) métodos de ensino; d) avaliação da aprendizagem; e) relação professor-aluno; e e) planejamento do trabalho.

a) Objetivos de aprendizagem. Dezenove professores indicaram a importância da formação oferecida pelas didáticas específicas para compreenderem os objetivos de aprendizagem, enquanto seis as consideraram pouco importantes. Esse aspecto é relevante tendo em vista que o trabalho pedagógico é responsável pela concretização de objetivos e metas expressas nos currículos e nos projetos políticopedagógicos das escolas. Com esse intuito, o professor desenvolve a atividade de forma intencional e planejada, consolidando o papel que compete à escola de socializar o conhecimento. Cabe destacar, no entanto, que as metas e os objetivos educativos expressos comportam determinações oriundas da dinâmica social moderna, moldada pelas relações sociais de produção da sociedade contemporânea. Isso porque, embora os alunos não estejam na condição de trabalhadores por ofício, ao se inserirem na organização do trabalho da escola e da sala de aula, são socializados para tal. Supõe-se, assim, a existência de uma lógica institucional de trabalho na escola, uma vez que os domínios econômicos, histórico-sociais, político-jurídicos, organizacionais e culturais convergem, nesse espaço, para uma relação social específica. 
Assim, ao definir os objetivos educativos, o professor deve observar a coerência interna entre objetivos gerais e específicos do currículo e do projeto político-pedagógico da escola, com consciência de que eles expressam expectativas de formação humana, acadêmica e profissional, sem desconsiderar as condições materiais de ensino e as características, interesses e necessidades discentes (VEIGA, 2008). Elaborar objetivos é, portanto, tarefa complexa por serem eles estruturantes do processo didático. Neles contemplam-se os conhecimentos culturais, habilidades, atitudes e valores da sociedade. $\mathrm{Na}$ formação docente, compete aos professores das disciplinas didáticas trabalhar para que os futuros professores compreendam os objetivos de aprendizagem articulados aos demais elementos estruturantes do trabalho pedagógico e aos interesses sociais, políticos e econômicos. Devem compreender, ainda, que essa elaboração não é uma questão meramente técnica e/ou neutra, mas reveladora de concepções de educação e de sujeito que se pretende formar, sendo, portanto, política e pedagogicamente determinada.

b) Conteúdos curriculares. Dezessete docentes indicaram a formação didática como relevante para a seleção e organização dos conteúdos curriculares, seis consideraram pouco importante e três, sem importância. Os conteúdos constituem a especificidade da escola, tendo em vista a função precípua de socialização dos conhecimentos histórica e socialmente elaborados que englobam conceitos, teorias, princípios, atitudes, hábitos, valores, entre outros.

Como na elaboração dos objetivos, a seleção e a organização de conteúdos curriculares deve ter como parâmetros a prática social dos sujeitos em formação, a contextualização, o significado, a relevância social e o reconhecimento das contradições que marcam o trabalho pedagógico e a sociedade e interferem não somente na seleção e organização dos conteúdos, mas também, no tratamento dado a eles junto aos estudantes. Essa tarefa é "realizada no processo de ensino, no qual se conjugam a atividade de direção e organização do ensino pelo professor e a atividade de aprendizagem e 
estudo dos alunos" (LIBÂNEO, 1993, p. 127). As didáticas são responsáveis pela abordagem dessas questões atinentes aos conteúdos curriculares: a Didática Geral contemplando aspectos gerais, como as finalidades, especificidades, critérios de seleção e organização, e as didáticas específicas com abordagens semelhantes, mas contemplando as particularidades do campo epistemológico das disciplinas.

c) Métodos de ensino. As percepções de dezenove egressos confirmaram a contribuição da formação vivenciada nas didáticas específicas para a seleção de métodos de ensino e desenvolvimento do trabalho pedagógico, enquanto sete deles se posicionaram de modo contrário. Desses, cinco declaram haver pouca contribuição e dois indicaram nenhuma contribuição nesse sentido. Os métodos de ensino possibilitam o alcance dos objetivos gerais e específicos, por meio de atividades docentes e discentes. São, portanto, “orientados para objetivos; implicam sucessão planejada e sistematizada de ações, tanto do professor quanto dos alunos; requerem a utilização de meios" (LIBÂNEO, 1993, p. 149). Nos anos finais do ensino fundamental, essa tarefa é fundante, tendo em vista o quão desafiador é desenvolver o processo didático para atender a um grupo de estudantes heterogêneo e plural, com interesses e expectativas muito diferentes e abrangentes, principalmente no atual contexto de sociedade, das novas tecnologias da comunicação e de informação.

Assim, a formação de sujeitos conscientes e críticos requer mudanças teóricas e metodológicas. Promovê-las requer dos professores ações didáticopedagógicas planejadas de forma consciente e crítica "com a finalidade de tornar o trabalho docente e discente mais fácil e produtivo para o alcance das metas desejadas e necessárias para o desenvolvimento integral dos educandos" (RAYS, 2006, p. 97). Desse modo, a formação didáticopedagógica oferecida nos cursos de licenciatura precisa contemplar o estudo de métodos de ensino de forma ampliada e crítica, o que implica ir além da ênfase na dimensão técnica e instrumental. 
Embora não devam ser compreendidos isoladamente, limitando a didática ao estudo de métodos de ensino, não há como negar a importância desse elemento para o desenvolvimento do trabalho pedagógico. Ele pode ser apontado como fator interveniente no desempenho estudantil que repercute nos altos índices de defasagem idade-série, como demonstram dados do Censo MEC/INEP (BRASIL, 2020). Destacamos que conforme Dados do Censo Escolar 2019 da Secretaria de Estado de Educação do DF a rede pública de ensino do DF atendia, à época da pesquisa, 124.414 estudantes dos anos finais do ensino fundamental, e apontam que 38.020, ou seja, 30,56\% deles estavam com idade defasada em relação ao ano escolar em curso. Os métodos de ensino devem, portanto, ser cuidadosamente discutidos nos processos formativos.

d) Avaliação da aprendizagem. Esta foi a categoria do trabalho pedagógico em que os docentes egressos mais consideraram que houve contribuição da formação didático-pedagógica, com vinte indicações. Quatro declararam pouca importância e apenas dois atribuíram nenhuma importância. Curiosamente, avaliar é uma prática que tem se mostrado muito complexa para os professores dos anos finais do ensino fundamental, se tomarmos como referência o alto índice de reprovação que engrossa as estatísticas de estudantes em defasagem idade-série nesta etapa da escolarização, conforme dito anteriormente. A avaliação é categoria fundamental para o trabalho pedagógico e "expressa relações de poder na escola e na sala, modulando o próprio acesso ao conteúdo e interfere, mais do que se possa pensar, no método de ensino escolhido para os alunos" (FREITAS et al,. 2009, p. 23).

$\mathrm{Na}$ rede pública de ensino do Distrito Federal, à qual se vinculam os professores que responderam o questionário, a organização escolar em ciclos implantada nos anos finais do ensino fundamental tem revelado certa incompreensão da função formativa da avaliação, comprometendo o trabalho do professor no que concerne à escolha do método e, em decorrência, a aprendizagem dos conteúdos pelos estudantes, conforme ressaltado por Freitas (Idem). 
Além disso, a avaliação da aprendizagem é conteúdo curricular pouco considerado na formação docente. Assim, a forma como o futuro professor é avaliado enquanto é aluno, seja na escola básica seja na licenciatura, muitas vezes irá guiar suas práticas avaliativas.

É possível que o número significativo de docentes que confirmam as contribuições das didáticas específicas para o trabalho pedagógico que desenvolve reflita a ênfase dada por parte dos pesquisadores aos procedimentos e instrumentos avaliativos, em especial aos exames, comumente utilizados sob o argumento de aferir conhecimentos, e não à avaliação como prática, como processo. Nessa perspectiva, as respostas sugerem que, na formação didática, a abordagem do tema se reduza a procedimentos e instrumentos, perspectiva que reforça a preocupação com o como fazer, como avaliar, ou seja, com a dimensão técnica do ato de avaliar.

e) Relação professor-aluno. Esta é uma categoria que foi reconhecida por dezoito professores como importante subsídio da formação didática oferecida no curso de licenciatura. Três declararam haver pouca contribuição nessa direção e cinco, nenhuma. Caracterizada como um conjunto de relações interpessoais que se desenvolvem no trabalho pedagógico, a relação pedagógica se efetiva nas interações e comunicações, na atividade coletiva voltada à construção de conhecimentos, significados, valores, atitudes e vínculos, orientados para a aprendizagem dos estudantes (PATTO, 1997; POSTIC, 2007). É na relação pedagógica que o professor transforma o conhecimento em conteúdo de ensinoaprendizagem, sem perder o vínculo desse conhecimento com a forma mais elaborada nem com as expressões espontâneas e cotidianas. Os conteúdos curriculares carecem de mediação entre a realidade de produção da vida social (campo produtivo), as contradições estruturais (problemas sociais) e a realidade escolar (campo formativo). Portanto, o conteúdo é o elemento central para concretizar a relação professor-aluno (POSTIC, 2007). Por não ser simples nem superficial, essa concretização deve merecer a atenção dos formadores de professores em todas as disciplinas dos currículos, mas, especialmente, nas 
didáticas geral e específicas e na Psicologia da Educação, reforçando, assim, a necessária articulação entre essas disciplinas pedagógicas no processo formativo.

f) Planejamento de ensino. Vinte professores reconheceram as contribuições das didáticas específicas para o planejamento de ensino, enquanto cinco consideram poucas as contribuições e apenas um não percebeu importância alguma desse estudo para a formação docente. O processo didático é um "sistema complexo de significados, de relações e de intercâmbios que ocorrem num cenário social que define as demandas de aprendizagem" (VEIGA, 2008, p. 269). Sua organização pressupõe, portanto, estruturação para materializar os objetivos e as intencionalidades desse processo. Mesmo que existam professores que, no exercício cotidiano da profissão, não sistematizam o trabalho pedagógico por meio do planejamento didático, é representativo o número dos que parecem reconhecer sua importância, atribuindo às aprendizagens oriundas das didáticas geral e específicas, um contributo para este fim.

Planejar o trabalho pedagógico pressupõe elaborar objetivos, selecionar e organizar conteúdos, metodologias e técnicas, recursos, e avaliar, e inclui a definição da função avaliativa que será adotada. Todo esse processo deve estar em consonância com a leitura de mundo, de realidade, o que lhe imprime sentido político-pedagógico por ser "uma atividade consciente e sistemática, em cujo centro está a aprendizagem ou o estudo dos alunos sob a direção do professor" (LIBÂNEO, 1993, p. 222). Daí a necessidade de que o estudo sobre planejamento se estenda para além da sala de aula, tendo em vista os diferentes níveis em que o trabalho pedagógico se realiza: escola, secretarias de educação e regionais de ensino.

A formação de professores exige, assim, reflexões acerca da concepção de educação e sua relação com a sociedade e a instituição educativa, bem como sobre o estudante a ser formado, sua cidadania e consciência crítica (VEIGA, 2008). Análises dessa natureza contribuem para que o trabalho pedagógico seja planejado a partir da realidade que se pretende modificar, 
distanciando-o de concepções que insistem em associá-lo a uma ação meramente técnica e burocrática.

\section{Pesquisa colaborativa: caminho para a construção do conhecimento e desenvolvimento acadêmico e profissional}

O grupo da pesquisa colaborativa é formado por docentes da educação superior e básica pública e por estudantes de graduação e pós-graduação que se reuniram espontaneamente, movidos pelo desejo de participar e estabelecer relações sociais, sem regulação e controle externo (FIORENTINI, 2019). Nessa perspectiva, quanto mais os pesquisadores interagem e se conhecem, mais a pesquisa vai se fortalecendo e produzindo "conjuntamente conhecimentos, os participantes adquirem autonomia e passam a auto-regular-se e a fazer valer seus próprios interesses" (Idem, p. 53).

O grupo contou com encontros sistemáticos para planejamento da pesquisa, estudos teóricos, elaboração e aplicação de instrumentos, organização, análise dos dados e escrita do relatório, com a prevalência de diálogo, negociações, acordos, trocas e interações que repercutiram na formação de todos.

A pesquisa colaborativa que integra pesquisadores da academia e professores da educação básica favorece o intercâmbio entre os conhecimentos produzidos sobre a formação didática dos licenciandos e o trabalho dos profissionais das redes de ensino, ampliando as possibilidades de reflexões e práticas didático-pedagógicas. Para os estudantes da graduação, a pesquisa com o ensino representou, "uma poderosa ferramenta de que se pode lançar mão para introduzir o aluno na iniciação científica, despertando-lhe o gosto pela investigação" (LAMPERT, 2008, p. 138), um espaço-tempo privilegiado de pensar novas alternativas para a formação do futuro professor da educação básica, ou seja, de realização da formação pela e na pesquisa.

Além disso, pesquisar a realidade de docentes da educação básica, tendo professores desse nível de ensino no grupo de pesquisa, nos oportunizou compreender, de maneira mais ampla e fidedigna, as práticas docentes. Isso 
suscitou novas problematizações acerca dos desafios que emergem no contexto da escola com os quais a universidade deve se comprometer promovendo o diálogo científico, acadêmico e pedagógico contributivos à produção de conhecimentos que promovam melhoria da educação básica pública.

A articulação promovida pela pesquisa colaborativa reveste-se de sentido político, interferindo na autonomia e tomada de consciência dos docentes, na sua práxis, a partir do momento em que suscita reflexões fundamentadas teoricamente acerca das suas concepções de mundo, de sujeito, de educação e de trabalho. Ela ressignifica ainda o compromisso dos docentes e da universidade com o cumprimento da função social que lhes cabe promover e articular - ensino, pesquisa e extensão.

A pesquisa colaborativa não é, no entanto, um mar sem turbulências. Ocorreram, nesse percurso, conflitos, dissensos, além das dificuldades inerentes a toda pesquisa com muitos sujeitos sociais e que são financiadas por agências de fomento, cujos prazos e exigências técnicas interferem nas relações entre os pesquisadores. Apesar disso, houve engajamento de todos no desenvolvimento da pesquisa e no cumprimento de objetivos e metas.

Dessa forma, entendemos que, pela pesquisa colaborativa, professores pesquisadores, licenciandos e pós-graduandos ampliaram sua visão de ensino e pesquisa compreendendo-os em sua totalidade como processo formativo pautado pela articulação teoria-prática e, de forma contextualizada, articulando-os aos espaços nos quais atuarão os professores da educação básica.

\section{Considerações finais}

Determinações econômicas e sociais de profunda desigualdade marcam as condições de vida e prejudicam sobremaneira o desempenho escolar, principalmente o de grupos sociais menos favorecidos. No entanto, os altos índices de estudantes cujas aprendizagens não condizem com o ano escolar em curso podem ter relação também com as práticas pedagógicas dos professores. 
Essas práticas não ocorrem em um vazio teórico, mas são subsidiadas teórica e metodologicamente por abordagens que não devem focalizar estritamente os conhecimentos específicos das áreas de conhecimento ou os métodos e técnicas de ensino. Para isso, as didáticas geral e específicas ofertadas nos cursos de licenciatura precisam contemplar fundamentos teórico-filosóficos educacionais e seus respectivos campos epistemológicos, visando a formação do professor crítico-reflexivo com condições de compreender a realidade e nela intervir, modificando-a.

Para isso, o trabalho pedagógico deve constituir processo intencional e sistemático de ensino-aprendizagem que se efetiva na relação professor-aluno, sendo orientado pela pedagogia como teoria da educação. Cabe à pedagogia, "de um lado, a identificação dos elementos culturais que precisam ser assimilados pelos indivíduos da espécie humana para que eles se tornem humanos e, de outro lado, e concomitantemente, a descoberta das formas mais adequadas para atingir esse objetivo" (SAVIANI, 2013, p. 13). Ratifica-se, assim, a necessária complementaridade entre a formação didático-pedagógica oportunizada pela didática de cunho mais geral e a relacionada aos conteúdos curriculares das áreas de conhecimento que compõem o currículo da educação básica, propiciada pelas didáticas específicas.

A didática geral e as didáticas específicas são intencionalmente vinculadas às finalidades sociais e políticas da educação, plurais e têm epistemologias, princípios e relações. Compreendem elementos comuns caracterizados como fundamentos gerais da educação e do ensino, e especificidades, na medida em que adentram os campos específicos das licenciaturas. Esses aspectos interferem no conteúdo e na forma de abordar o ensino e a docência em cada curso e nas disciplinas correspondentes.

As discussões teórico-práticas apresentadas neste texto resultam da pesquisa colaborativa que investigou a formação e o trabalho docente constituindo-se em possibilidades formativas para professores pesquisadores da escola básica, estudantes de iniciação científica e pesquisadores da universidade. Nessa articulação todos se fortalecem: os estudantes da 
graduação que vivenciam a formação pela pesquisa; os da pós-graduação que se inserem em grupos de pesquisa colaborativa e constroem conhecimentos teóricos e metodológicos que resultarão em uma formação na perspectiva da práxis; os professores pesquisadores, por ser a pesquisa contributiva ao seu desenvolvimento profissional; a universidade que, na articulação com as redes de ensino, reafirma o seu protagonismo acadêmico, político e social na produção de conhecimento a partir da realidade concreta da escola; e a escola e seus profissionais que, no diálogo com os resultados da pesquisa, podem refletir sobre o trabalho pedagógico e a formação necessária para atuar didática e pedagogicamente visando ensinar para emancipar.

Por fim, na atual conjuntura política e educacional do País, de constantes ataques à educação pública, à pesquisa e ao conhecimento científico, pesquisar colaborativamente é ato de resistência.

\section{Referências}

BERBEL, N. A. N. Didática e práxis. II Jornada de Didática e I Seminário de Pesquisa do CEMAD: docência na educação superior - caminhos para uma práxis transformadora. 2013.

BRASIL. Instituto Nacional de Estudos e Pesquisas Educacionais Anísio Teixeira (Inep). Censo da Educação Básica 2020: Notas Estatísticas. Brasília-DF, 2021.

BRASIL. Plano Nacional de Educação 2014-2024: Lei n. 13.005, de 25 de junho de 2014, que aprova o Plano Nacional de Educação (PNE) e dá outras providências. Brasília: Câmara dos Deputados, Edições Câmara, 2014.

DISTRITO FEDERAL. Dados gerais do Censo 2019. SEE/SUPLAV/DINFE/GETED. Disponível em: http://dadoseducacionais.se.df.gov.br/dadosgeraiscenso.php. Acesso em: 08 jun. 2021.

DISTRITO FEDERAL. Caderno de Matrículas 2019. Secretaria de Educação do Distrito Federal. Disponível em: http://www.se.df.gov.br. Acesso em: 08 jun. 2021.

DUARTE, N. Os conteúdos escolares e a ressurreição dos mortos: contribuição à teoria histórico-crítica do currículo. Campinas: Autores Associados, 2016.

FIORENTINI, D. Pesquisar práticas colaborativas, ou pesquisar colaborativamente? In: BORBA, M. C.; ARAÚJO, J. L. (Orgs.). Pesquisa qualitativa em educação matemática. Belo Horizonte: Autêntica Editora, 2019, p. 47-76.

FRANCO, M. L. P. B. Análise do Conteúdo. Brasília-DF: Líber Livro Editora, 2008. 
FREITAS, Luíz Carlos de; SORDI, Mara Regina Lemes de; MALAVASI, Maria Márcia Sigrist; FREITAS, Helena Costa Lopes de. Avaliação Educacional: Caminhando pela contramão. Petrópolis-RJ: Vozes, 2009.

LAMPERT, E. O ensino com pesquisa: realidade, desafios e perspectivas na universidade brasileira. In: Docência na educação superior. Linhas Críticas, Brasília, v. 14, n. 26, p. 5-24, jan./jun. 2008. DOI:

https://doi.org/10.26512/lc.v14i26.3439.

LIBÂNEO, J. C. Didática. São Paulo: Cortez, 1993.

LIBÂNEO. Didática e epistemologia: para além do debate entre a didática e as didáticas específicas. In: VEIGA, I. P. A.; D'AVILA, C. (orgs.). Profissão Docente: novos sentidos, novas perspectivas. Campinas, SP: Papirus, 2008.

LINELL, P. Dialogical language, dialogical minds, dialogical brains. In: Conference on Cognitive Dynamics and the Language Sciences. Cambridge, UK, 2009.

LIMA, J. A. As culturas colaborativas nas escolas. Portugal, Porto Editora, 2002.

MÉSZÁROS, I. A educação para além do capital. Tradução de Isa Tavares. $2^{\mathrm{a}}$ ed. São Paulo: Boitempo, 2008.

PALUDO, C.; VITÓRIA, F. B. Contribuições do materialismo histórico-dialético para o entendimento da política pública social na atualidade. In: CUNHA, C.; SOUSA, J. V.; SILVA, M. A. (Orgs.). O método dialético na pesquisa em educação. Campinas: Autores Associados, 2014. p. 99-130.

PATTO, M. H. S. Introdução à psicologia escolar. São Paulo: Casa do Psicólogo, 1997.

PIMENTA, S. G. FRANCO, M. A. S; FUSARI, J. C. Didática multidimensional: da prática coletiva à construção de princípios articuladores. Anais do XVII Encontro Nacional de Didática e Prática de Ensino. Universidade do Estado do Ceará, 2014.

PIMENTA, S. G. Movimentos críticos da Didática: resistência ao tecnicismo/neotecnicismo neoliberal. Presença Pedagógica na sala de aula. Ed. 146, ano 23, novembro de 2018. Rona Editora. Belo Horizonte: MG, p. 12-21

POSTIC, M. A relação pedagógica. 2 ed. Coimbra, Portugal: Editora Coimbra Ltda., 2007.

RAYS, O. A. Metodologia de ensino: Cultura do caminho contextualizado. In: VEIGA, I. P. A. (org.). Repensando a didática. Campinas: Papirus, 2006.

SÁNCHEZ VÁZQUEZ, A. Filosofia da práxis. São Paulo: Expressão Popular, 2007.

SAVIANI, D. Pedagogia histórico-crítica: primeiras aproximações. $11^{\mathrm{a}} \mathrm{ed}$. Campinas, SP: Autores Associados, 2013. 
SOARES, E. R. M.; FERNANDES, R. C. A. Trabalho Pedagógico Colaborativo no Ensino Fundamental. In: VEIGA, I. P. A.; FERNANDES SILVA, E. Ensino Fundamental: da LDB à BNCC. Campinas, SP: Papirus, 2018.

SHIROMA, E. O.; CAMPOS, R. F.; GARCIA, R. M. C. Decifrar textos para compreender a política: subsídios teórico-metodológicos para análise de documentos. Revista Perspectiva, Florianópolis, v. 23, n. 2, p. 427-446, jul/dez, 2005. DOI: https://doi.org/10.5007/\%25x.

TCHALEKIAN, B. B. A. Os Sentidos e Significados atribuidos por uma professora da rede pública de ensino de São Paulo aos impasses e dificuldades para a realização da atividade docente. Projeto financiado pelo Conselho de Ensino, Pesquisa e Extensão da PUC-SP e certificado pela coordenadora Wanda Maria Junqueira de Aguiar em 02/01/2014. Disponível em: http://www.pucsp.br/iniciacaocientifica/22encontro/artigos-premiados21ed/BRUNA-B-A-TCHALEKIAN.pdf. Acesso em: 09 jun. 2021.

VEIGA, I. P. A. Organização didática da aula: um projeto colaborativo de ação imediata. In: VEIGA, I. P. A. (Org.). Aula: gênese, dimensões, princípios e práticas. Campinas, SP: Papirus, 2008.

VEIGA, I. P. A.; FERNANDES SILVA, E. Para onde vão a didática geral da educação superior e as didáticas específicas? In: VEIGA, I. P. A.; FERNANDES, R. C. A. Por uma didática da educação superior. Campinas, SP: Editora Associados, 2020, p. 41-60.

WACHOWICZ, L. A. O método dialético na didática. Campinas, SP: Papirus, 1989.

ZABALZA, A. O ensino universitário: seu cenário e seus protagonistas. Porto Alegre: Artmed, 2004. 